\title{
Cuidados em pacientes com doença de Parkinson na odontologia: revisão narrativa
}

\author{
Care in patients with Parkinson's disease in dentistry: narrative review
}

\section{Cuidado en pacientes con enfermedad de Parkinson en odontología: revisón narrativa}

José Milton de Aquino e Silva Neto ${ }^{1 *}$, Jysllene Nataly Victor Lucas ${ }^{1}$, Vívian Rodrigues Vilar ${ }^{1}$, Ana Tereza de Vasconcelos Aquino e Silva ${ }^{2}$, Jessika Nathalia Victor Lucas ${ }^{1}$, José Murilo Barbosa dos Santos $^{1}$, Michelle Leão Bittencourt Brandão Medeiros ${ }^{1}$, Tayguara Cerqueira Cavalcanti ${ }^{1}$.

\section{RESUMO}

Objetivo: Ressaltar, por meio de uma revisão de literatura narrativa, as apresentações integrais e orais da Doença de Parkinson (DP), bem como demonstrar as precauções no decorrer da assistência odontológica dos respectivos pacientes. Revisão bibliográfica: A DP é uma enfermidade das quais causa degeneração, gradativa das quais não possui cura, suas origens não são conhecidas, afeta especialmente pessoas com faixa etária entre os 40 e 65 anos de idade. Causa prejuízo aos sistemas motores, especialmente, tremores em inatividades, inflexibilidade da musculatura, bradicinesia, acinesia, inconstância na fisionomia, passos arrastados, posturas inadequadas, fala turva, dos quais refletem em uma imensa inabilidades de efetuar tarefas do cotidiano, como pode-se citar a higienização bucal. Os recursos terapêuticos baseia-se na atenção dos presságios, no entanto não diminui a sua evolução. Pacientes com DP exibem sintomatologias bucais, principalmente nos elementos dentais e maxilo-faciais, como dificuldade na deglutição, excesso de saliva ou falta dela, impressão de ardor oral, problemas no uso de próteses dentárias, tornando assim o suporte odontológico bastante trabalhoso e cauteloso. Considerações Finais: Para o estabelecimento de um bom resultado o Cirurgião Dentista necessita conhecer os fatores limitantes de cada paciente de forma particularizada, estando o profissional adequadamente habilitado para atender esses pacientes.

Palavras-chave: Assistência ambulatorial, Doença de Parkinson, Saúde bucal.

\begin{abstract}
Objective: Highlight, through a review of narrative literature, the full and oral presentations of Parkinson's Disease (DP), as well as demonstrate the precautions during the dental care of the respective patients. Literature review: DP is a disease from which it causes degeneration, gradual of which has no cure, its origins are not known, it affects especially people aged between 40 and 65 years old. It causes damage to the motor systems, especially, tremors in inactivity, inflexibility of the muscle, bradykinesia, akinesia, inconsistency in the physiognomy, dragged steps, inadequate postures, blurred speech, which reflect in an immense inability to perform daily tasks, as can be seen mention oral hygiene. The therapeutic resources are based on the attention of omens, however it does not slow its evolution. DP patients exhibit oral symptoms, especially in the dental and maxillofacial elements, such as difficulty in swallowing, excess of saliva or lack of it, impression of oral burning, problems in the use of dental prostheses, thus making dental support very laborious and cautious. Final Considerations: In order to establish a good result, the Dental Surgeon needs to know the limiting factors of each patient in a particular way, with the professional being properly qualified to assist these patients.
\end{abstract}

Keywords: Ambulatory care, Parkinson disease, Oral health.

${ }_{1}^{1}$ Centro Universitário CESMAC (CESMAC), Maceió - AL. *E-mail: milton_neto_166@hotmail.com

${ }^{2}$ Universidade Estadual de Ciências da Saúde de Alagoas (UNCISAL), Maceió - AL. 


\section{RESUMEN}

Objetivo: Destaque, a través de una revisión de la literatura narrativa, las presentaciones completas y orales de la enfermedad de Parkinson (DP), y demuestre las precauciones durante el cuidado dental de los respectivos pacientes. Revisión bibliográfica: La DP es una enfermedad de la que causa degeneración, de la cual gradualmente no tiene cura, se desconocen sus orígenes, afecta especialmente a personas de entre 40 y 65 años. Causa daños en los sistemas motores, especialmente, temblores en la inactividad, inflexibilidad del músculo, bradicinesia, acinesia, inconsistencia en la fisionomía, pasos arrastrados, posturas inadecuadas, habla borrosa, que se refleja en una inmensa incapacidad para realizar las tareas diarias, como se puede ver mencionar higiene bucal. Los recursos terapéuticos se basan en la atención de los presagios, sin embargo, no frena su evolución. Los pacientes con DP presentan síntomas orales, especialmente en los elementos dentales y maxilofaciales, como dificultad para tragar, exceso de saliva o falta de ella, impresión de ardor oral, problemas en el uso de prótesis dentales, lo que hace que el soporte dental sea muy laborioso y cauteloso. Consideraciones finales: Con el fin de establecer un buen resultado, el cirujano dental necesita conocer los factores limitantes de cada paciente de una manera particular, con el profesional debidamente calificado para ayudar a estos pacientes.

Palabras clave: Atención ambulatoria, Enfermedad de Parkinson, Salud bucal.

\section{INTRODUÇÃO}

A enfermidade da Doença de Parkinson (DP) é um distúrbio patológico do qual provoca a degeneração do paciente sendo uma doença irreparável, dos quais degeneram os neurotransmissores provocados por receptores dopaminérgicos de constituição das substâncias escuras dos gânglios basais cerebrais que são estruturas que possibilita múltiplas interligações diretas com o tálamo e o córtex cerebral, onde se inicia um início de ciclo. A DP possui sua origem ainda desconhecida, porém é observado que seu processo evolutivo decorre de maneira lenta e evolutiva de acordo com o aumento da idade do paciente, sendo atingido na maioria das vezes pessoas que possuem 40 e 65 anos (MOLLENHAUER B, et al., 2016).

Apresentam como fundamentais sintomatologias: a rigidez muscular, diminuição ou ausência total dos movimentos do corpo, lentificação dos movimentos voluntários, tremores quando o paciente encontra-se em repouso e fragilidade na postura do paciente portador (BATISTA LM, et al., 2015). No entanto, consegue do mesmo modo ser encarada como sendo multissistêmica, visto que sensibiliza também diferentes regiões do sistema nervoso central, acarretando indícios de início de depressão, formas alucinógenas no aspecto visual e até mesmo provocar demências (LESCANO SS, 2013).

É uma patologia dos quais atingem o sistema neurológico que possui elevado predomínio, encontrandose 80 a 160 casos à cada 100 mil pessoas, acometendo ao menos $1 \%$ da sociedade que possui faixa etária maior que 65 anos. A grande maioria dos casos ocorridos acontecem entre o sexo masculino, embora que essa doença não possua distinção, podendo ser encontrada mutuamente em homens e mulheres (GOLDMAN JG, et al., 2018).

Apesar de sua forma etiológica não ser conhecida, determinados fatores relacionados aos genes, a hereditariedade, determinadas toxinas presentes no ambiente, fatores que provocam situação de excesso de radicais livres em comparação com o sistema protetor intrínseco de cada célula nesse caso o estresse, conseguem colaborar com o surgimento da DP. Na maioria das vezes as toxinas que causam essa patologia e estão presentes no ambiente são encontrados em pacientes que moram no meio rural, em que utilizam água de poços artesianos do qual mantém-se mais susceptível ao contato direto ou indireto de produtos químicos utilizado no campo como é o caso dos compostos manganês e mercúrio que são os mais encontrados. Enquanto o estresse de forma oxidativa ocorre devido a divergência na hora da constituição dos radicais livres e os agentes de defesa antioxidativos. Os fatores correspondentes a genética encontram-se relacionados aos genes que simplificam o surgimento dessa patologia, enquanto os fatores de irregularidades mitocondriais relacionam causas tóxicas e fatores genéticos decorrente da morte celular planejada (SAVICA $R$, et al., 2018). 
Esse aspecto patológico geralmente começa a se apresentar na parte superior do corpo de maneira unilateral, determinando desta forma a falta de simetria estabelecida pela decomposição inicial no cérebro. Portanto, o aspecto de mãos tremulas ocorre em apenas em uma, seguidamente nos membros inferiores do mesmo lado que acometeu a mão, para só assim ir para outros membros (NOGUEIRA AF, 2016). Esses indivíduos apresentam uma forma expressiva de rosto fechado, como se estivesse utilizando uma máscara, sem demonstrar sentimentos, a voz é bastante afetada, isso ocorre por causa da inexistência do controle sobre a musculatura facial e da laringe. E diversas sintomatologias como descontinuidade no fluxo de fala caracterizada por repetições, grande ansiedade, problema no aprendizado, falta de sono e perda do olfato (FERREIRA JJ, et al., 2017).

Para se diagnosticar um paciente com Doença de Parkinson é necessário se basear em aspectos clínicos, analisando detalhes na hora da anamnese e observar sua flexibilidade motora, solicitando exames e trabalhando com uma equipe multiprofissional (NOGUEIRA AF, 2016). A validação das sintomatologias observadas no exames solicitados irá necessitar do reconhecimento de 2 ou mais sinais motores, como os que já foram apresentados, além do teste de sorológicos, de imagens, tomografia e ressonância para só assim obter um diagnóstico preciso. O reconhecimento da DP pode ser eventualmente persuadido por inúmeros fatores, como a durabilidade dos tremores, a idade, e o conhecimento do profissional capacitado. Assim sendo, é necessário observar as peculiaridades existentes de um paciente para outro (SAVICA R, et al., 2018).

Mesmo a doença não possuindo cura, pode-se amenizar os sinais e sintomas, utilizando determinadas drogas, sendo a Levodopa o fármaco de primeira seleção para os recursos terapêuticos da DP. A Levodopa pode ser prescrita isoladamente ou junto com outro medicamento, porém essa droga pode possuir efeitos indesejáveis como é o caso de: xerostomia, o ranger dos elementos dentais, modificação de paladar e a hipotensão ortostática (NOGUEIRA AF, 2016).

Levando em consideração os aspectos relacionados a saúde oral do paciente que apresenta essa patologia, uma das principais atenções que devem serem levadas em consideração é a questão da higienização. Com o avanço da patologia, o paciente portador da DP não consegue possuir a capacidade de executar de forma precisa a escovação bucal, precisando assim da ajuda de pessoas próximas para o bom desempenho. A visita ao consultório odontológico deve ser feita corriqueiramente, visto que um dos maiores problemas são as cáries e doenças periodontais (MANCOPES R, et al., 2013).

Mesmo que as análises, experimentos e estudos controlados sobre essa temática encontrem-se gradativamente mais elevados, os aspectos que envolvem a saúde oral do paciente com DP nos dias atuais não são descritos adequadamente e os resultados obtidos na literatura em sua grande parte são controversos. Desta forma isso pode ser apto de forma direta em influenciar negativamente o nível de conhecimento e habilidade do Cirurgião Dentista (CD) na assistência e suporte desses indivíduos (BATISTA LM, et al., 2015).

Portanto, este estudo tem como principal fundamento, através de uma revisão de literatura, analisar as manifestações que ocorrem em pacientes com Doença de Parkinson não só de forma geral, mas sim observar os aspectos bucais estabelecendo e identificando os cuidados que os Cirurgiões Dentistas devem possuir na hora do atendimento desses pacientes de forma mais cautelosa.

\section{REVISÃO BIBLIOGRÁFICA}

\section{Manifestações clínicas da Doença de Parkinson}

A Doença de Parkinson apresenta-se como uma forma de problema neurodegenerativo progressivo, crônico e fatal, dos quais sua decorrência ainda continua sendo desconhecida no meio científico, podendo ser apresentada com sintomatologia motora ou não. Pode ser observado nove principais características dos sintomas motores dessa enfermidade (FARLOW MR, 2010; NOGUEIRA AF, 2016).

Os tremores apresentam-se como sendo os sinais iniciais na maioria dos pacientes, situando-se nas extremidades distais dos membros superiores, geralmente nos dedos das mãos e inferiores pernas e pé. Seu 
início apresenta-se clinicamente de forma assimétrica, em ocorrência de 4 a 7 intervalos por segundo (O'REGAN G, et al., 2017).

Os aspectos relacionados a rigidez define-se por meio do acrescentamento do fortalecimento muscular em que ocorre quando uma parcela do corpo é deslocado de forma passiva. Em cada associação muscular encontra-se outra das quais executam funções opostas, denominado como antagonista. Sendo assim, na ocasião em que o grupo muscular é conduzido com o objetivo de reproduzir definidas formas de movimentos, em ocasiões normais o seu antagonista é obstruído para beneficiar essa mobilidade. Nessa patologia, essa forma de bloqueio não decorre de maneira eficiente. Deixando por sua vez a musculatura mais distendidas e contraídas, por consequência o indivíduo portador dessa patologia fica mais rígido e dispondo de pouca locomobilidade (NOGUEIRA AF, 2016).

Ocasiona a bradicinesia em que é a delonga para executar determinada movimentação e Acinesia que é a falta de capacidade de começar um determinado motilidade ou demora no período de resposta (SILVA FS, et al., 2010; PEREIRA CGD, 2010). O indivíduo que apresenta Doença de Parkinson apresenta diminuição na mobilidade natural em todo seu âmbito, como escovação dos dentes, limpar o rosto, pegar em algum objeto. A face mais anterior do rosto possui menor movimentação, com diminuição na constância das piscadas dos olhos, e suas emoções não são tão expressivas (MOLLENHAUER B, et al., 2016; GOLDMAN JG, et al., 2018).

As modificações posturais do portador dessa patologia é alterada pelo fato de ocorrer uma prevalência da musculatura flexora de maneira em que a cabeça se acondiciona curvada sobre o tronco, enquanto o tronco fica sobre 0 abdome já os membros superiores encontram-se moderadamente à frente, com o parte da extremidade superior entre o cotovelo e o carpo pouco flexionado na estatura do cotovelo, essa postura faz com quer ocorra modificações posturais na coluna vertebral (LESCANO SS, 2013).

O portador da Doença de Parkinson apresenta o tom de voz de forma hipofónico devido a uma falta de coordenação dos músculos da fala. Pode-se constatar também que poucos desses pacientes apressam os ritmos na hora de se expressar com palavras, atropelando algumas silabas, fazendo com quer as pessoas que estejam ao seu redor não entendam direito. Esses pacientes apresentam caligrafias tremulas e pequenas, além de boa parte apresentarem osteoporose, para minimizar o efeito são apresentados a eles processos terapêuticos antiparkinsonianas sendo particularizada de um indivíduo para outro (BATISTA LM, et al., 2015).

Vários pacientes apresentam formas de ação ativa conhecida como congelamento dos quais 0 ato de caminhar não pode ser executado temporariamente. Isso ocorre porque o indivíduo portador dessa patologia não consegue mudar o sentido da sua direção (PEREIRA CGD, 2010). Processos de deglutição e mastigação torna-se um problema bastante significativo para esses portadores visto que os tecidos musculares responsáveis pelo processo de engolir faz com quer aumente o número de salivação e sua deglutição tornase tarefa difícil e lenta podendo até sufocar o paciente (HOUSER MC, et al., 2018).

Outros fatores que podem ser levado em consideração é o distúrbio do sono, isso se deve ao fato dos pacientes não conseguirem relaxar, com bastante frequência eles despertam a noite por causa dos movimentos bruscos que apresentam, o medicamento Levedopa ajuda ao que se refere a uma melhor benefício na qualidade do sono noturno, podendo ser associado com medicamentos indutores do sono. Os distúrbios cognitivos comprometem de forma relevante esses paciente podendo causar ansiedade, síndromes metabólicas. Uma das maiores queixas desses paciente são as dores e fadigamento musculares em várias regiões do corpo, principalmente nos membros superiores e regiões lombares causando inúmeras câimbra sendo provocada por uma contração vigorosa e involuntária de um ou mais grupamentos musculares (GOLDMAN JG, et al., 2018).

\section{Possíveis causas da Doença de Parkinson}

Embora tenha havido muitos avanços na pesquisa de pacientes com DP nas últimas décadas, A causa é revelada e é definida como idiopática em que o seu significando pode ser surgido espontaneamente ou de causa obscura ou desconhecida. Alguns trabalhos científicos demostraram que essa enfermidade é ocasionada devido uma série de fatores que colaboram para o seu surgimento e avanço, sendo eles: Fatores 
genéticos cuja herança se caracteriza por mecanismos complexos de transmissão envolvendo múltiplos genes herdados dos pais, fatores ambientais, dano neuronal, por diversos motivos, como falta de oxigênio (isquemia), trauma ou doença. Estresse oxidativo em que é a situação de excesso de radicais livres em comparação com o sistema protetor intrínseco de cada célula, deficiência mitocondrial em que ocorre a diminuição da atividade das mitocôndrias, e / ou excitotoxicidade do qual é um processo patológico pelo qual células nervosas são danificadas ou mortas por estimulação excessiva por neurotransmissores (PILOTTO A, et al., 2015; (NOGUEIRA AF, 2016).

Considera-se que a DP esteja ligada diretamente as formas genéticas suscetíveis, visto que em média $20 \%$ da Doença de Parkinson nesses pacientes têm ao menos um parente de primeiro grau com essa enfermidade sendo ela uma herança autossômica dominante. Com relação aos fatores ambientais, inúmeros estudos vinculam DP em portadores que moram em áreas rurais dos quais utilizam água de poço e vivem próximos de industrias e trabalham em minerações, sendo expostos diretamente a produtos químicos como pesticidas e herbicidas (MATOS PC B e DECESARO MN, 2012; BATISTA LM, et al., 2015; SAVICA R, et al., 2018).

Apesar de todas essas associações com a Doença de Parkinson, até o presente momento, não existe evidências científicas convincentes em que comprovem que existe uma interrelação de causa e efeito entre fatores de toxicidade ambiental e o desenvolvimento de PD (LOANE G e POLITIS M, 2011). No mecanismo de dano neuronal, o número de neurônios diminui devido a existência pigmentos na substância negra do qual é uma porção heterogênea do mesencéfalo responsável pela produção de dopamina no cérebro. Além do que, na teoria do estresse os radicais livres oxidantes analisados reage com outras moléculas para produzir oxidação. Este tratamento bioquímico é nocivo para vários componentes celulares (como mitocôndrias e membranas celulares). Podendo causar a morte dessas células. Geralmente o corpo se livra dessas Moléculas não desejadas, entretanto, existem muitos radicais livres na substância negra em que causam ou agravam o processo de desnaturação celular (SOUSA CF, et al., 2011).

\section{Diagnóstico da DP}

O seu diagnóstico é baseado em uma minuciosa e cuidadosa avaliação clínica. É de suma importância a eficácia do profissional saber fazer uma boa anamnese através da história clínica, exame físico, exames complementares e prestar a atenção em dois ou mais sinais locomotores do indivíduo. Até os dias de hoje não há nenhum exame complementar de qualquer tipo para provar com firmeza o diagnóstico (SOUZA CFM, et al., 2011; HOUSER MC, et al., 2018).

Inúmeras causas podem contribuir com a investigação da DP, entre elas pode-se destacar a durabilidade que determinadas sintomatologias começaram, a idade do indivíduo e por fim, porém não menos importante o conhecimento científico e prático do profissional responsável. Por esse motivo é fundamental e indispensável uma anamnese detalhada, e exame clínico consistindo em avaliar e analisar o paciente através da inspeção, palpação, ausculta e percussão tendo bastante atenção nos problemas físicos e possíveis fatores psicológicos que podem serem relacionados. Nos estágios iniciais da doença, é dificultoso distinguir seus sinais e sintomas e dos quais podem passarem desatentamente por causa das modificações normais que acontecem no envelhecimento (NOGUEIRA AF, 2016).

\section{Manifestações bucais}

Encontra-se por vezes várias manifestações na cavidade oral dos pacientes que sofrem com essa patologia, segundo Nogueira AF (2016) uma das características que podem serem observadas no consultório odontológico são: a dificuldade de deglutir a própria saliva ou engolir um alimento, sinais de sialorreia, em alguns pacientes podem ocorrer a hipossalivação, existindo a comoção de bastante dores na cavidade bucal, cárie e doença periodontais devido à falta de flexibilização no ato da escovação.

\section{Disfagia}

Esse fenômeno ocorre devido a modificações ocorridas no processo de deglutição. Quando o indivíduo portador da DP tem bastante dificuldade em se alimentar de forma liquida ou solida, a saúde bucal e geral 
são bastante prejudicadas, e uma das principais preocupações é não conseguirem fazer a utilização de medicamento via oral (GOLDMAN JG, et al., 2018).

Outras sintomatologias que acarretam a cavidade bucal bastante corriqueiro de disfagia acontece com o refluxo do ácido do estômago ou a bile quando entra no tubo alimentar e irrita a mucosa, tendo por consequência a erosão dos elementos dentais, aumento assim o índice de sensibilidade nos dentes. Precisase fazer o acompanhamento desse paciente e indicar o mesmo a possuir uma rotina de fazer bochechos com água após cada refluxo acometido tendo como propósito diminuir a quantidade de ácido nos elementos dentais (NOGUEIRA AF, 2016).

\section{Sialorreia}

Esse termo é designado aos pacientes que apresentam grande quantidade de salivação, dos quais considera-se como sendo uma alteração do fluxo salivar secundário. Podendo ser relacionado à grande quantidade de medicações ou até mesmo ao grau da doença existente em cada paciente. Um dos fatores que desencadeiam essa desordem é relacionado ao problema de mastigação e delimitação dos tônus presentes na muscular da face (LEEHEY M, et al., 2017).

\section{Xerostomia}

É quando o paciente apresenta sensações de boca seca, esse estado é apontado como sendo uma das manifestações orais mais comum em indivíduos que tem Doença de Parkinson, essa condição presente nos pacientes acarretam de forma significativa as porcentagens de surgimentos de cárie e doenças periodontais (NOGUEIRA AF, 2016). Sendo comprovado cientificamente que o fluxo salivar alterado tanto na concentração, quanto no potencial hidrogeniônico $(\mathrm{pH})$ causa grande prejuízo na cavidade bucal do indivíduo, posto que a saliva ajuda no processo de limpeza da cavidade oral, sendo bastante importante no equilíbrio dos ácidos existentes e na preservação através da remineralizarão do esmalte dental. Além do que, pode intervir na fonética, ocasionar processos ulcerativos, incômodo oral com aparecimento de aftas, eritemas e parestesias (STOESSI AJ, 2012).

Buscando disponibilizar um melhor bem-estar, pode-se indicar determinadas condutas para esses pacientes: bebendo água com constância e utilização de comprimidos mastigáveis a base de xilitol sem possuir concentração de açúcares. Porém se a situação do paciente estiver muito grave devido a secura da boca e dores existentes na musculatura impossibilitando o processo de mastigação, pode-se prescrever adjuntos salivares de carboximetilcelulose e que apresente flúor em pequena concentração (NOGUEIRA AF, 2016).

\section{Ardor oral}

Conhecida com a denominação de síndrome da boca ardente, é frequentemente relacionada a xerostomia e a drogas com Levodopa, dos quais incentiva o processo de funcionalidade alterada da musculatura dos quais essa deficiência é ocasionada pelo déficit de minerais, vitamínicas ou até mesmo da desregulação hormonal (BATISTA LM, et al., 2015). As regiões que são mais agredidas por essa patologia é o dorso da língua, lábios superiores e inferiores, palato duro e as estruturas anatômicas presentes nos rebordos alveolares de pacientes edêntulos. Esses indivíduos possuem a predisposição de possuírem pouco apetite, acarretando diminuição significativa do peso corporal e dificuldade de adaptação da utilização de sua prótese dentária (NOGUEIRA AF, 2016).

\section{Cárie dentária e doença periodontal}

Os pacientes acometidos com essa patologia possuem maior predisposição de possuírem cárie, isso ocorre por causa das suas limitações no ato da escovação dos dentes, principalmente os elementos dentais posteriores, eles não conseguem fazer higienização com fio dental ou até mesmo limpar suas próteses, precisando sempre da ajuda de um profissional ou alguém próximo, a cárie mais comumente presente estão localizadas na parte cervical e radicular, esse acontecimento deve-se as raízes expostas por conta da idade, esses fatores citados fazem com quer surjam inflamações locais, ocasionando problemas periodontais, por esses motivos é de estrema importância a ida ao consultório odontológico (CICCIÙ M, et al., 2012). 


\section{Medidas que o cirurgião dentista deve tomar na hora do atendimento}

O primeiro contado do CD com os pacientes com DP necessita de uma atenção especial, buscando sempre cautela, serenidade e determinação, para o paciente ficar relaxado, procurando todas as maneiras viáveis diminuir as barreiras que o indivíduo possua. A clínica responsável por esses atendimentos especializados deve possuir acessibilidade, de maneira que os pacientes que utilizam algum tipo de apoio como bengalas, andarilhos, ou até mesmo cadeira de rodas sejam capazes de adentrar e se movimentar de maneira simples, possuindo sua autonomia (MANCOPES R, et al., 2013).

Desde o primeiro contato com o paciente portador da DP, a finalidade dos processos terapêuticos precisam serem preservadas com a comodidade do bem-estar, a autonomia, buscando sempre compreender e escutar 0 paciente. Independentemente que o processo possua dificuldades, necessita possuir uma conduta especificada para obter uma comunicabilidade com o paciente, a não ser que o paciente apresente um quadro de demência grave em que ocorra o impedimento do diálogo, desta forma deve-se informa todos os procedimentos a serem realizados para o responsável presente (CICCIÙ M, et al., 2012).

$\mathrm{Na}$ hora da anamnese deve-se obter detalhadamente do quadro clínico, com o objetivo de saber todas as deficiências psicossociais, laudos médicos, os fármacos que são empregues, analisar a hora mais cômoda para a assistência e suporte odontológico. Dessa maneira, elaborar um planejamento particularizado de um paciente para outro, levando sempre em consideração as limitações do paciente. É de suma importância observar temperatura, pulso, respiração e a pressão arterial (BATISTA LM, et al., 2015).

Deve-se obter conforto e sessões rápidas, de maneira que minimize o estresse e a decorrência do acréscimo de tremores, habitualmente é aconselhável que os atendimentos sejam realizadas após uma hora depois de tomar os fármacos, visto que nesse intervalo os tremores diminuem. Não se aconselha inclinar a cadeira odontológica em 45ำ, por causa das dificuldades de deglutição expostos por esses pacientes. E logo assim que terminar o tratamento a cadeira deve ser vagarosamente colocada no posicionamento vertical, precautelando possível a queda excessiva da pressão arterial (MANCOPES R, et al., 2013).

\section{CONSIDERAÇÕES FINAIS}

Como esta patologia possui modificações de aspectos motores e cognitivos, toda a equipe multiprofissional em que trata com recursos terapêuticos devem estarem engajados de forma direta com esses indivíduos, tendo que dispor do reconhecimento ao que se refere as manifestações orais da Doença de Parkinson, principalmente os cirurgiões dentistas, porque eles implicam em sua condição clínica. É de suma relevância que os dentistas entendam o verdadeiro significado de cada sinal e sintoma dessa doença, a fim de fazer um plano de tratamento correto e sigam sempre as restrições impostas pelos pacientes em questão, Os procedimentos feitos na cavidade oral devem serem considerados como de fundamental importância como prevenção, principalmente quando a doença está em estágio inicial, buscando dessa maneira minimizar possíveis necessidades de recursos terapêuticos mais invasivos, de acordo com o avanço da doença. Além de que, o CD carece dispor de estimulação e direcionar tanto o portador da doença como sua família na motivação e instrução de técnicas de higiene oral buscando sempre empregar em sua residência a forma correta de escovação, sem ininterrupção ao tratamento para só assim obter uma disposição de vida elevada na cavidade bucal desses pacientes.

\section{REFERÊNCIAS}

1. BATISTA LM, et al. Oral Hygiene in Patients with Parkinson's Disease. R I Med J, Providence, 2015; 98(11): 35-37.

2. CICCIÙ M, et al. Periodontal Helth and caries Prevalence evaluation in patients affected by parkinson's Disease. Parkinsons Dis. 2012.

3. FARLOW MR. Alzheimer disease. In: Fillit HM, Rockwood K, Woodhouse K. Brocklehurst's Textbook of geriatric medicine and gerontology. Philadelphia: Elservier; 2010; 7: 411-20.

4. FERREIRA JJ, et al. Prevalence of Parkinson's disease: population-based study in Portugal. Eur J Neurol. 24,2017: 748-750.

REAS/EJCH | Vol.12(11) | e4828 | DOI: https://doi.org/10.25248/reas.e4828.2020 Página 7 de 8 
5. GOLDMAN JG, et al. Cerebrospinal fluid, plasma, and saliva in the bioFIND study: relationships among biomarkers and Parkinson's disease features. Mov Disord. 2018; 33: 282-288.

6. HOUSER MC, et al. Stool imune profiles evince gastrointestinal inflammation in Parkinson's disease. Mov Disord., 2018; 33: 793-804.

7. LEEHEY M, et al. Association of metabolic syndrome and change in Unified Parkinson's Disease rating scale acores. Neurology. 2017; 89: 1789-1794.

8. LESCANO SS. Investigação de queixa específica de deglutição para medicamentos em pacientes com diagnóstico de doença de Parkinson. Trabalho de conclusão de curso (Bacharelado em Fonoaudiologia) - Universidade Federal do Rio Grande do Sul, Porto Alegre, 2013.

9. LOANE G, POLITIS M. Positron emission tomography neuroimaging in Parkinson's disease. American Journal of Translational Research, 2011; 3(4): 323-341.

10. MANCOPES R, et al. Influence of levodapa on the oral phase of sawllowing in patients with Parkinson's disease. Rev CEFAC, 2013; 15(3): 707-712.

11. MATOS PC B, DECESARO MN. Características de idosos acometidos pela doença de Alzheimer e seus familiares cuidadores principais. Revista Eletrônica de Enfermagem, 2012 v.14, n. 4: 857-865.

12. MOLLENHAUER B, et al. Biological confounders for the values of cerebrospinal fluid proteins in Parkinson's disease and related disorders. 2016, 139, supl 1: 290-317.

13. NOGUEIRA AF. A doença de Parkinson e suas implicações na saúde oral. 2016. Dissertação (Mestrado em Medicina Dentária) - Instituto de Ciências da Saúde Egas Moniz, Portugal, 2016.

14. O'REGAN G, et al. Glucocerebrosidase mutations in Parkinson disease. J Parkinsons Dis. 2017; 7:411-422.

15. PEREIRA CGD. Factores de risco da doença de Parkinson - um estudo epidemiológico. Acta Med Port, Portugal, 2010; 23(1): 15-24.

16. PILOTTO A, et al. Developments in the role of transcranial sonography for the diferential diagnosis of parkinsonism. Curr Neurol Neurosci Rep. 2015: 15-43.

17. SAVICA R, et al. When do a-Synucleinopathies start? Na epidemiological timeline a review. JAMA Neurol. 2018; 75: 503-509.

18. SILVA FS, et al. Evolução da doença de Parkinson e comprometimento da qualidade de vida. Rev Neurocienc, Maringá, 2010; 18(4): 463-468.

19. SOUSA CF, et al. A Doença de Parkinson e o Processo de Envelhecimento Motor: Uma Revisão de Literatura. Rev Neurocien, São Paulo, 2011; 19(4): 718 -723.

20. SOUZA CFM, et al. Doença de Parkinson e o Processo de Envelhecimento Motor: Uma Revisão de Literatura. Rev Neuro Mos. 2011; 19(4):718-23.

21. STOESSI AJ. Neuroimaging in Parkinson's disease: from pathology to diagnosis. Parkinsonism Relat Disord. 2012; 8: 72-81. 